\title{
Inhibition of allorecognition by a human class II MHC-derived peptide through the induction of apoptosis
}

\author{
Barbara Murphy, ${ }_{1}^{1}$ Colm C. Magee, ${ }^{2}$ Stephen I. Alexander, ${ }^{2}$ Ana Maria Waaga, ${ }^{2}$ \\ Hans W. Snoeck, ${ }^{1}$ John P. Vella, ${ }^{2}$ Charles B. Carpenter, ${ }^{2}$ and Mohamed H. Sayegh ${ }^{2}$ \\ ${ }^{1}$ Renal Division, Mount Sinai School of Medicine, New York, New York 10128, USA \\ ${ }^{2}$ The Laboratory of Immunogenetics and Transplantation, Renal Division, Brigham and Women's Hospital, Harvard Medical School, \\ Boston, Massachusetts 02115, USA \\ Address correspondence to: Barbara Murphy, Renal Division, Mount Sinai School of Medicine, 1 Gustave L. Levy Place, New York, \\ New York 10128, USA. Phone: (212) 241-5850; Fax: (212) 987-0389; E-mail: Barbara_Murphy@smtplink.mssm.edu
}

Received for publication November 6, 1998, and accepted in revised form January 26, 1999.

\begin{abstract}
The interaction of the T-cell receptor with the major histocomatibility complex (MHC)-peptide complex is central to T-cell activation. Variation in the nature of the peptide bound within the groove of the MHC molecule may result in an altered $\mathrm{T}$-cell response. Because some naturally processed peptides bound within the groove of the class II MHC molecule are derived from the MHC molecules themselves, we studied the inhibitory effects of synthetic class II MHC peptides on alloimmune responses in vitro. Three peptides derived from a highly conserved region of the class II MHC $\alpha$ chains inhibited the rat mixed lymphocyte response (MLR) in a dose-dependent manner, with the human HLA-DQA1 peptide also inhibiting the human and mouse MLR. No effect was seen on mitogen-induced T-cell proliferation. HLA-DQA1 inhibited cytolytic T lymphocyte (CTL) generation in a dose-response fashion, with no reduction in preformed CTL killing, suggesting that the inhibitory effect is targeted at $\mathrm{CD} 4^{+} \mathrm{T}$-cell function. Cell-cycle analysis by flow cytometry showed that restimulation of primed T cells in the presence of HLA-DQA1 resulted in increased apoptosis, whereas unstimulated cells were not affected. These data demonstrate that synthetic peptides derived from highly conserved regions of the class II MHC $\alpha$ chain can alter CD4 $4^{+} \mathrm{T}$-lymphocyte alloimmune responses in vitro, and this effect is mediated by the induction of apoptosis in activated T cells.
\end{abstract}

J. Clin. Invest. 103:859-867 (1999).

\section{Introduction}

Recent insights into the structure and function of the major histocompatibility complex (MHC) molecules have enabled a better understanding of the interaction of the T-cell receptor (TCR) with the MHC-peptide complex on the surface of antigen-presenting cells (APCs) and have highlighted the important role of the peptide in determining the subsequent T-cell response. The MHC molecule is a highly specialized structure, forming a complex with a peptide fragment that is then presented on the cell surface for recognition by $\mathrm{T}$ lymphocytes. Interaction between the TCR with a complementary MHC-peptide complex, in conjunction with that between other T-cell surface molecules and their respective ligands, triggers a cascade of intracellular events culminating in T-cell activation and differentiation. This response is central to the immune response to alloantigens. Variation in the nature of the peptide bound within the groove of the MHC molecule has been shown to result in an altered T-cell response in vitro (1). Findings by Chicz et al. in humans $(2,3)$ and by Hunt et al. in mouse (4) demonstrate that naturally processed peptides bound within the groove of the class II MHC molecule are predominantly derived from endogenous proteins including the MHC molecules themselves. The processing of MHC molecules by self-APCs may therefore be a physiologic event with important immunomodulatory functions in vivo (5). A peptide derived from the $\alpha 1$ helical region of HLA-
DQA*03011 has already been shown to inhibit T-cell proliferation through the interruption of cell-cycle progression (6). We now report on the distinct immunomodulatory functions and mechanisms of action of another class II MHC $\alpha$ chain-derived peptide.

\section{Methods}

Class II MHC peptides. We synthesized four 15- to 16-mer peptides, two derived from human class II MHC: HLA-DQA1 (residues 62-77 of the $\alpha$ chain of DQA*0101) and HLADQB1 (corresponding residues of the $\beta$ chain of DQB $1 * 0501)$ chain, and two derived from rat class II MHC: RT1.D ${ }^{u} \alpha$ (residues 61-75) and RT1. ${ }^{u} \alpha$ (residues 62-78). The peptides were synthesized by Chiron Mimotopes (Victoria, Australia) using an automated peptide synthesizer. Peptides were purified by reverse-phase HPLC and shown to be $>95 \%$ homogenous by analytical reverse HPLC and mass spectroscopy. RT1.D $\beta_{2}$ (residues 20-44), a Wistar-Furth (WF) class II MHC peptide, was synthesized in the Protein/Nucleic Acid Laboratory, Brigham and Women's Hospital, Department of Medicine $(7,8)$. Before use, the peptides were dissolved in sterile PBS at a concentration of $1 \mathrm{mg} / \mathrm{ml}$. Peptide sequences are shown in Table 1.

Animals. Male Lewis (LEW), Wistar-Furth (WF), and Brown Norway (BN) rats, 8-12 weeks old, were obtained from Harlan-Sprague-Dawley (Indianapolis, Indiana, USA). Adult male CBL/6j and DBA mice, 4-6 weeks old, were purchased from The Jackson Laboratory (Bar Harbor, Maine, USA).

Rat mixed lymphocyte response. Cervical lymph nodes were har- 
vested from naive LEW, WF, and BN rats, and the lymphocytes were isolated as described previously (9). The cells were then washed twice and resuspended in RPMI-1640 medium (BioWhittaker Inc., Walkersville, Maryland, USA), containing 10\% FCS, $100 \mathrm{U} / \mathrm{ml}$ penicillin and $100 \mu \mathrm{g} / \mathrm{ml}$ streptomycin, $2 \times 10^{-5} \mathrm{M} 2$ mercaptoethanol, and $5 \mathrm{mM}$ HEPES. Responder rat lymph node cells $\left(3 \times 10^{5}\right)$ were cultured in 96-well flat-bottom microtiter plates (Corning-Costar Corp., Cambridge, Massachusetts, USA) with an equal number of irradiated (30 Gy) stimulator cells. Serial dilutions of the peptides $(10-0.078 \mu \mathrm{g} / \mathrm{ml})$ were added at the initiation of cultures. Positive-control wells were set up with no peptide added, and negative-control wells were set up with responder cells and culture medium only. The plates were incubated at $37^{\circ} \mathrm{C}$ with $5 \% \mathrm{CO}_{2}$ for $96 \mathrm{~h}$, with addition of $\left[{ }^{3} \mathrm{H}\right]$ thymidine $(1 \mu \mathrm{Ci}$ /well; Du Pont NEN Research Products, Boston, Massachusetts, USA) for the last $6 \mathrm{~h}$ of culture. Cells were then harvested with a Tomtec Harvester 96 (Tomtec Inc., Hamden, Connecticut, USA). Proliferation was assayed by $\left[{ }^{3} \mathrm{H}\right]$ thymidine uptake. All experiments were set up in quadruplicates, and results expressed as percent inhibition, which was calculated as follows:

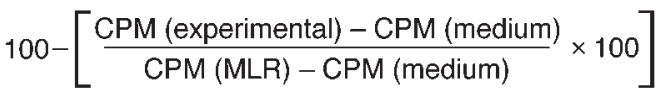

Delayed peptide addition studies, i.e., in which peptide was added to the rat mixed lymphocyte response (MLR) at various periods after coincubation of the LEW and WFx lymphocytes, were also performed. In certain cases, either responder or stimulator cells were incubated with peptide for $2 \mathrm{~h}$ at $37^{\circ} \mathrm{C}$ and then washed to remove unbound peptide before being added to the MLR culture.

Mouse MLR. Splenic lymphocytes were isolated from naive CBL/6j and DBA mice by Histopaque 1083 (Sigma Chemical Co., St. Louis, Missouri, USA), and the cells were then washed twice and resuspended as just described for the rat lymphocytes. CBL/6j responder lymphocytes $\left(5 \times 10^{5}\right)$ were cultured in 96-well flat-bottom microtiter plates (Corning-Costar Corp.) with an equal number of irradiated (30 Gy) DBA stimulator cells. Control and experimental wells were set up as in the rat MLR with serial dilutions of the peptides $(100-0.78 \mu \mathrm{g} / \mathrm{ml})$. The plates were incubated for $72 \mathrm{~h}$ with addition of $\left[{ }^{3} \mathrm{H}\right]$ thymidine for the last $18 \mathrm{~h}$ of culture.

Human MLR. Peripheral blood mononuclear cells (PBMCs) from normal human volunteers were isolated by Ficoll-Paque (Pharmacia Biotech, Uppsala, Sweden) density gradient centrifugation. Proliferation of responder cells $\left(2 \times 10^{5}\right)$ to an equal amount of irradiated stimulator cells was tested in the standard one-way MLR assay. Briefly, cell mixtures were cultured in 96well round-bottom microtiter plates (Corning-Costar Corp.) for 6 days with serial dilution of peptides $(100-0.78 \mu \mathrm{g} / \mathrm{ml})$ and harvested after $18 \mathrm{~h}$ incubation with $\left[{ }^{3} \mathrm{H}\right]$ thymidine.

Cytotoxic T-cell generation and cytotoxic T-cell function. The cytotoxic T-cell generation assay was performed as described previously (9). To generate LEW cytotoxic T cells, equal numbers of responder LEW and irradiated stimulator WF cervical lymph node cells were incubated for 7 days at a concentration of $1 \times$ $10^{6} \mathrm{cells} / \mathrm{ml}$ in bulk cultures with or without different doses of peptides. LEW effector cells were harvested from LEW-WFX bulk cultures and washed. WF lymphocytes that had been incubated in the presence of Concanavalin A $10 \mu \mathrm{g} / \mathrm{ml}$ for $48 \mathrm{~h}$ were used as target cells. The WF targets were harvested, washed, and labeled with $0.4 \mu \mathrm{Ci}$ of sodium chromate- 51 in $50 \mu \mathrm{l}$ of FCS for $2 \mathrm{~h}$ at $37^{\circ} \mathrm{C}$. Effector cells were then washed three times and suspended at $1 \times 10^{5} / \mathrm{ml}$. Effector $(\mathrm{E})$ and target $(\mathrm{T})$ cells were then add to 96-well round-bottom microtiter plates (CorningCostar Corp.) at E/T ratios of 100:1 and 50:1. For determination of maximum and spontaneous release, target cells were incubated with isoterge detergent and medium alone, respectively. After incubation, $50 \mu \mathrm{l}$ of supernatant from each well was collected, and the amount of ${ }^{51} \mathrm{Cr}$ release was counted using a $\beta$-scintillation counter. The degree of lysis was calculated using the following formula:

\section{$\%$ lysis $=\left[\frac{\mathrm{CPM}(\text { experimental })-\mathrm{CPM}(\text { spontaneous })}{\mathrm{CPM}(\text { maximum })-\mathrm{CPM}(\text { spontaneous })} \times 100\right]$}

To test the effect of peptides on the cytolytic activity of preformed cytotoxic $T$ cells rather than on the generation of such cells, LEW cytotoxic T cells generated from LEW-WF bulk cultures in the absence of peptide were incubated with different doses of peptides and ${ }^{51} \mathrm{Cr}$-labeled WF targets. The degree of lysis was calculated as already described.

Rat proliferation to mitogen. Responder LEW lymph node cells $\left(2 \times 10^{5} /\right.$ well $)$ were stimulated with Con A $(10 \mu \mathrm{g} / \mathrm{ml})$ with or without peptide $(100-0.78 \mu \mathrm{g} / \mathrm{ml})$ in 96 -well flat-bottom microtiter plates (Corning-Costar Corp.). Negative-control wells were set up with culture medium only (background control). Proliferation was assayed by $\left[{ }^{3} \mathrm{H}\right]$ thymidine uptake at 48 $h$ after $6 \mathrm{~h}$ incubation.

Human proliferation to mitogen. Responder PBMCs $(2 \times$ $10^{5} /$ well) were stimulated with phytohemagglutinin (PHA) $(10$ $\mu \mathrm{g} / \mathrm{ml})$ with or without peptide $(100-0.78 \mu \mathrm{g} / \mathrm{ml})$ in 96 -well round-bottom microtiter plates (Corning-Costar Corp.). Negative-control wells were set up with culture medium only (background control). Proliferation was assayed by $\left[{ }^{3} \mathrm{H}\right]$ thymidine uptake on day 3 after $18 \mathrm{~h}$ of incubation.

Proliferation to superantigen. Responder LEW lymph node cells $\left(2 \times 10^{5} /\right.$ well $)$ were stimulated with toxic shock syndrome toxin1 (TSST-1; $25 \mathrm{ng} / \mathrm{ml}$ ) or staphylococcal endotoxin E (SEE; 10 $\mathrm{ng} / \mathrm{ml})$ with or without peptide $(100-0.78 \mu \mathrm{g} / \mathrm{ml})$ in 96-well flat-bottom microtiter plates (Corning-Costar Corp.). Negativecontrol wells were set up with culture medium only (background control). Proliferation was assayed by $\left[{ }^{3} \mathrm{H}\right]$ thymidine uptake at $72 \mathrm{~h}$ after $6 \mathrm{~h}$ of incubation.

Cytokine analysis by ELISA. Cytokine analysis was performed on supernatants collected from human MLRs cultured alone or in the presence of HLA-DQA1 or HLA-DQB1 peptides $(100 \mu \mathrm{g} / \mathrm{ml})$ for 1-7 days. In addition dose-response studies were performed with HLA-DQA1 or HLA-DQB1 peptides $(100-0.78 \mu \mathrm{g} / \mathrm{ml})$ on the days of peak cytokine production. Interleukin-2 (IL-2) and interferon- $\gamma($ IFN- $\gamma)$ production were quantified by ELISA using Endogen ELISA kits (Endogen Inc., Boston, Massachusetts, USA). All wells were set up in duplicate, and values were expressed as picograms per milliliter derived from the standard curve. In the event that cytokine production was higher than the highest standard, dilutional studies were performed. IFN- $\gamma$ production in the rat MLR was also assayed over a 5-day course by ELISA using BioSource Cytoscreen Rat IFN- $\gamma$ ELISA kits (BioSource International, Camarillo, California, USA).

Inbibition of MLR and cytokine production with HLA-DQA1 peptide combined with CTLA4Ig. Suppression of lymphocyte proliferation in the human MLR with either low-dose CTLA4Ig or HLA-DQA1 peptide alone or in combination was examined. The concentration of CTLA4Ig required to produce a $30 \%$ inhibition of the human MLR was determined by serial dilutions $(10-0.01 \mu \mathrm{g} / \mathrm{ml})$, and the effect of adding this dose to low-dose HLA-DQA1 $(5 \mu \mathrm{g} / \mathrm{ml})$ on the proliferative response in the human MLR was determined. Proliferation was measured by thymidine incorporation as already described here, and HLA-DQB1 peptide was used as control.

Priming to the indirect pathway of allorecognition by immunization. Inbred responder LEW rats were primed by immunization subcutaneously in the footpad with $100 \mu \mathrm{g}$ of the WF peptide RT1.D ${ }^{\mathrm{u}} \beta_{2}$ (residues $20-44$ ) in complete Freund's adjuvant. One week after immunization, popliteal lymph nodes were harvest- 
ed and the lymphocytes were isolated as described previously (8). The cells were then washed twice and resuspended into RPMI1640 medium (BioWhittaker, Walkersville, Maryland, USA), containing 10\% FCS, 100 $\mathrm{U} / \mathrm{ml}$ penicillin and $100 \mu \mathrm{g} / \mathrm{ml}$ streptomycin, $2 \times 10^{-5} \mathrm{M} 2$-mercaptoethanol, and 5 mM HEPES. Responder lymphocytes $(2 \times$ $10^{5}$ ) were cultured in 96-well flat bottom plates (Corning-Costar Corp.) with 50 $\mu \mathrm{g} / \mathrm{ml}$ of the RT1.D $\beta_{2}$. Serial dilutions of either HLA-DQA1 or HLA-DQB1 peptides $(100-0.78 \mu \mathrm{g} / \mathrm{ml})$ were added at the initiation of cultures. Positive-control wells were set up with the immunogenic RT1.D ${ }^{\mathrm{u}} \beta_{2}$ alone, and negative-control wells were set up with responder cells and culture medium only. The plates were incubated at $37^{\circ} \mathrm{C}$ with $5 \% \mathrm{CO}_{2}$ for $96 \mathrm{~h}$ with addition of $\left[{ }^{3} \mathrm{H}\right]$ thymidine $(1$ $\mu \mathrm{Ci} /$ well; Du Pont NEN Research Products) for the last $6 \mathrm{~h}$ of culture. Cells were then harvested with a Tomtec Harvester 96 (Tomtec). Proliferation was assayed by $\left[{ }^{3} \mathrm{H}\right]$ thymidine uptake.

Allospecific T-cell clones. We have established T-cell clones from LEW animals that are specific to the indirect recognition of RT1.D ${ }^{\mathrm{u}} \beta_{2}(20-44)$, i.e., self-restricted to recognize and respond to the allopeptide RT1.D $\beta_{2}(20-44$; refs. 10,11$)$. T cells clones $(2.5 \times$ $\left.10^{4}\right)$ were stimulated with naive LEW APCs $\left(1 \times 10^{5}\right)$ pulsed with RT1.D ${ }^{\mathrm{u}} \beta_{2}(20-44)$ in the presence of increasing doses of either HLA-DQA1 or HLA-DQB1 peptides $(100-0.78 \mu \mathrm{g} / \mathrm{ml})$ in 96-well flat-bottom plates (Corning-Costar Corp.). The plates were incubated at $37^{\circ} \mathrm{C}$ with $5 \% \mathrm{CO}_{2}$ for $48 \mathrm{~h}$ with addition of $\left[{ }^{3} \mathrm{H}\right]$ thymidine $(1 \mu \mathrm{Ci} /$ well; Du Pont NEN Research Products) for the last 6 $\mathrm{h}$ of culture. Cells were then harvested with a Tomtec Harvester 96 (Tomtec). Proliferation was assayed by $\left[{ }^{3} \mathrm{H}\right]$ thymidine uptake.

Proliferation to autoantigen. Inbred responder LEW rats were primed by immunization subcutaneously in the footpad with $50 \mu \mathrm{g}$ of the major encephalitogenic epitope of guinea pig myelin basic protein (MBP) peptide $71-90$, in CFA $(12,13)$. The peptide was synthesized at the Biopolymer Center, Center for Neurologic Diseases, Brigham and Women's Hospital. One week after immunization, popliteal lymph nodes were harvest$\mathrm{ed}$, and the lymphocytes were isolated and resuspended in medium as described for preparation of cells from animals immunized with RT1.D $\beta_{2}(20-44)$. Responder lymphocytes (2 $\times 10^{5}$ ) were cultured in 96-well flat-bottom plates (CorningCostar Corp.) with $50 \mu \mathrm{g} / \mathrm{ml}$ of the MBP 71-90 in the presence or absence of either HLA-DQA1 or HLA-DQB1 peptides $(100-0.78 \mu \mathrm{g} / \mathrm{ml})$. Plates were set up, incubated, and harvested as already described here for proliferation of lymphocytes primed to RT1.D ${ }^{\mathrm{u}} \beta_{2}(20-44)$.

Quantitation of apoptosis by flow cytometry. Cells primed to RT1.D ${ }^{\mathrm{u}} \beta_{2}$ by immunization were prepared as described in the preceding paragraph and suspended at a concentration of $10^{6}$. Cells were then restimulated with RT1.D $\beta_{2}(50 \mu \mathrm{g} / \mathrm{ml})$ alone, or in the presence of HLA-DQA1 or HLA-DQB1 peptides (100 $\mu \mathrm{g} / \mathrm{ml})$. Responder cells and culture medium only served as negative control. Cells were taken at $1 \mathrm{~h}, 24 \mathrm{~h}$, and 3 days and washed once in cold sterile $0.1 \%$ dextrose (J.T. Baker, Philipsburg, New Jersey, USA) in PBS. The cells were then fixed in 70\% ethanol and stored at $4{ }^{\circ} \mathrm{C}$ until FACS ${ }^{\circledR}$ analysis was performed. At this time, cells were spun at $1,500 \mathrm{~g}$ and resuspended in 300 $\mu \mathrm{l}$ Rase $(50 \mu \mathrm{g} / \mathrm{ml}$; Sigma Chemical Co.) and $300 \mu \mathrm{l}$ propidium iodide $(50 \mu \mathrm{g} / \mathrm{ml}$; Calbiochem-Novabiochem Corp., San Diego, California, USA). Flow cytometric analysis was performed on a FACStar Plus (Becton Dickinson Immunocytometry Systems, Mountain View, California, USA), equipped with a water-cooled argon laser, emitting at $488 \mathrm{~nm}$. The flow cytometer was calibrated for fluorescence and compensation settings using Calibrite beads (Becton Dickinson Immunocytometry Systems). Cells $\left(5 \times 10^{3}\right)$ were acquired for each sample.

\section{Results}

Inbibition of MLR. We examined the ability of the four class II MHC peptides to inhibit the rat one-way MLR. We found that the three peptides derived from the highly conserved region of the $\alpha$ chains of HLA-DQ, RT1.B and RT1.D, inhibited the LEW-WFx MLR in a dose-response manner, whereas the $\beta$ chain-derived peptide of HLADQB1 had no inhibitory effect (Fig. 1a). The three $\alpha$-chain peptides differed, however, in the concentration at which they achieved complete suppression of the rat MLR: HLADQA1 and RT1.B $\alpha$ peptides were extremely potent, requiring a concentration of only $10 \mu \mathrm{g} / \mathrm{ml}$ and $1.25 \mu \mathrm{g} / \mathrm{ml}$, respectively, whereas $250 \mu \mathrm{g} / \mathrm{ml}$ of RT1.D $\alpha$ peptide was necessary. All three allelic peptides also inhibited different responder: stimulator combinations in the rat MLR, with complete inhibition of the BN-WFx and the LEW-BNx MLRs at the same doses required for the LEW-WFx MLR.

The peptides were next tested for their ability to inhibit the human MLR. HLA-DQA1 peptide produced complete inhibition of the human MLR at $100 \mu \mathrm{g} / \mathrm{ml}$ (Fig. 1b). This inhibitory effect was independent of the responder-stimulator combination, as five responders of differing HLA types were inhibited in the response to two stimulators, also of different tissue typing, with $100 \%$ inhibition at 100 $\mu \mathrm{g} / \mathrm{ml}$ HLA-DQA1. In addition, the pattern of dose-response did not vary among responders or stimulators. RT1.B $\alpha$ peptide, the most potent inhibitor of the rat MLR, was not as significant an inhibitor of the human MLR, with $42.6 \pm 10.23 \%$ inhibition at $100 \mu \mathrm{g} / \mathrm{ml}$. Neither RT1.D $\alpha$ nor HLA-DQB1 peptides had any inhibitory effect. It was further demonstrated that HLA-DQA1 peptide also suppressed the mouse MLR (Fig. 1c); thus, its inhibitory effect was not species specific.

The HLA-DQA1 peptide was a potent inhibitor of the MLR in all three species. All further experiments to characterize the function of these nonpolymorphic peptides were carried out using this peptide. HLA-DQB1 peptide, which was noninhibitory, was used as control. Delayed addition of $10 \mu \mathrm{g} / \mathrm{ml}$ HLA-DQA1 peptide to the LEW-WFx MLR at time 0 (the beginning of the assay) +5 , $+15,+30$, or +60 minutes resulted in $102 \%, 76 \%, 55 \%, 46 \%$, and $28 \%$ inhibition respectively. These data indicate that HLA-DQA1 peptide affects early events in T-cell activation. Furthermore, preincubation of either the LEW responder or WF stimulator cells with HLA-DQA1 peptide for two hours followed by washing to remove excess peptide did not result in any inhibition of the MLR. However, if responder and stimulator cells were incubated together for two hours with HLA-DQA1 and then washed, $49.3 \%$ suppression of the MLR resulted. Thus, for optimal suppression of proliferation, HLA-DQA1 peptide is required at the 
time of T cell-APC interaction and initial T-cell activation.

Inbibition of $T$ cell-mediated cytotoxicity. We next tested the effect of HLA-DQA1 peptide on T cell-mediated cytotoxicity. HLA-DQA1 peptide inhibited the generation of cytotoxic $\mathrm{T}$ lymphocytes in a dose-response manner. Incubation of LEW responders and WF stimulators with HLA-DQA1 peptide at $10 \mu \mathrm{g} / \mathrm{ml}$ for seven days prior to the cytotoxic assay decreased the percentage of

$a$

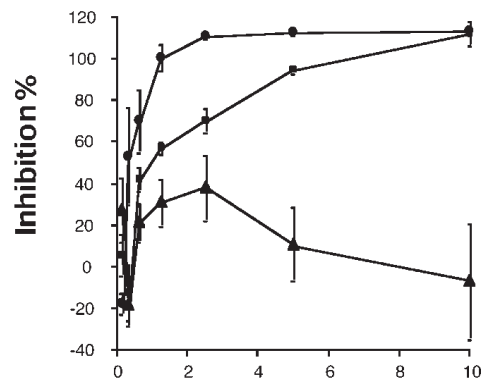

$b$

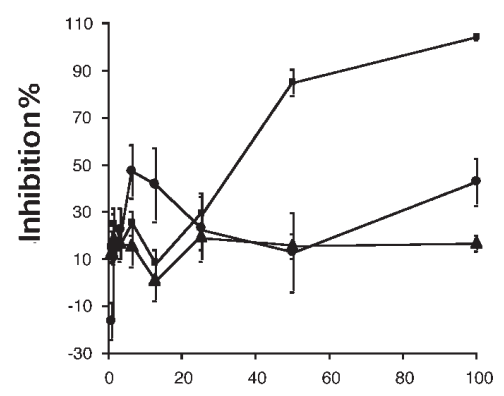

$\boldsymbol{c}$

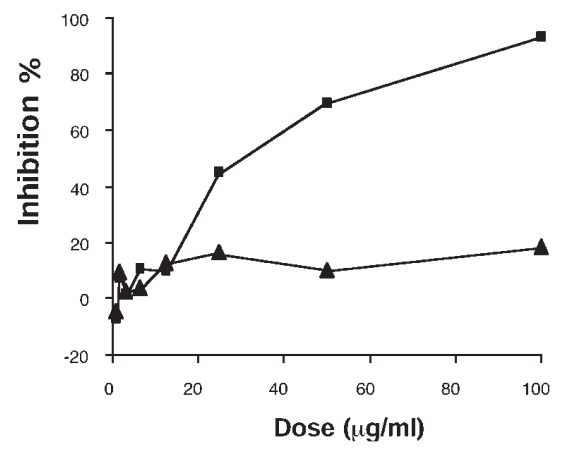

$$
\begin{array}{ll}
\longrightarrow & \text { HLA-DQA1 } \\
\longleftarrow & \text { HLA-DQB1 } \\
\bullet & \text { RT1.B Alpha }
\end{array}
$$

\section{Figure 1}

(a) Effects of peptides derived from HLA-DQA1, HLA-DQB1, and RT1. $\mathrm{B} \alpha$ on the LEW-WFx rat MLR $(n=3)$. Peptide derived from RT1. D ${ }^{u} \alpha$ required a concentration of $250 \mu \mathrm{g} / \mathrm{ml}$ to cause $100 \%$ inhibition of proliferation (data not shown). (b) Effects of peptides derived from HLADQA1 and HLA-DQB1 on the human MLR $(n=6)$. Results are expressed as percent inhibition of the proliferative response in the presence of the individual peptides and represent the mean \pm SEM for each experiments. (c) Effects of peptides derived from HLA-DQA1 and HLA-DQB1 on the mouse MLR. Results are expressed as percent inhibition of the proliferative response of the mouse MLR (C57/BL-DBAx) in the presence of the individual peptides and represent the mean of quadruplicate wells of a typical experiment. $M L R$, mixed lymphocyte response. target cells specifically lysed by responder cells from 28.7 $\pm 13.5 \%$ (unmodified controls) to $0.67 \pm 0.89 \%$. In contrast, incubation with HLA-DQB1 peptide at $10 \mu \mathrm{g} / \mathrm{ml}$ resulted in specific lysis of $27.3 \pm 6.9 \%$ of target cells. (Effector/target ratios of 100:1 used; $n=3$ ). However, addition of HLA-DQA1 peptide at the beginning of the incubation of mature effector cells with the chromiumlabeled targets had no inhibitory effect on cell lysis. Thus, HLA-DQA1 peptide does not affect the cytolytic activity of preformed cytotoxic $\mathrm{CD}^{+} \mathrm{T}$ cells, indicating that the inhibitory effect is targeted at $\mathrm{CD} 4^{+} \mathrm{T}$-helper function or early stages of $\mathrm{CD}^{+} \mathrm{T}$-cell activation.

Mitogen-induced T-cell proliferation. When LEW lymphocytes were stimulated with mitogen (ConA) in the presence of HLA-DQA1 peptide, there was no significant inhibition of the proliferative response at $10 \mu \mathrm{g} / \mathrm{ml}$, the dose that resulted in $100 \%$ inhibition of the rat MLR. By increasing the dose of HLA-DQA1 peptide 10 -fold, only $62.3 \pm 1.7 \%$ suppression was achieved. Similarly, HLA-DQA1 peptide did not inhibit proliferation of human lymphocytes stimulated with PHA, although proliferation was increased with the control HLA-DQB1 peptide at all doses (Fig. 2).

Superantigen-induced T-cell proliferation. LEW lymphocytes stimulated with superantigen in the presence of HLADQA1 peptide showed $72.7 \pm 8.1 \%$ (TSST- 1 ) and $69.4 \pm$ $6.9 \%$ (SEE) inhibition of the proliferative response at 100 $\mu \mathrm{g} / \mathrm{ml}$. This compared with $2.6 \pm 8.9 \%$ inhibition of proliferation to TSST-1, and $13.7 \pm 3.7 \%$ to SEE, when the control peptide HLA-DQB1 was added to the cultures. These data indicate that the HLA-DQA1 peptide inhibits lymphocyte proliferative response to superantigens.

Inbibition of IL-2 and IFN- $\gamma$ production. We examined the effect of HLA-DQA1 peptide on cytokine production by human T lymphocytes. Supernatants were taken from human MLRs incubated in the absence of peptide or with increasing doses of either HLA-DQA1 or HLADQB1 peptides over a period of seven days. In the control MLR, IL-2 was detected on days 2, 3, and 4, with peak levels on day 3 . IL-2 production into the medium was completely inhibited throughout the time course by HLA-DQA1 peptide at $100 \mu \mathrm{g} / \mathrm{ml}$. The effect of HLADQA1 peptide on IL-2 production was dose-dependent (Fig. $3 a$ ) and similar to the effect on proliferation, with inhibition at higher doses (Fig. $1 b)$. IFN- $\gamma$ was detected throughout the seven-day study period in the control MLR. However, incubation with HLA-DQA1 peptide 100 $\mu \mathrm{g} / \mathrm{ml}$ completely suppressed IFN- $\gamma$ production on days $1-5$, with minimal amounts detected on days 6 and 7 $(3.3 \mathrm{pg} / \mathrm{ml}$ and $17.2 \mathrm{pg} / \mathrm{ml}$, respectively), compared with levels of greater than $1,000 \mathrm{pg} / \mathrm{ml}$ on these days in the control cultures. The inhibition of IFN- $\gamma$ by HLA-DQA1 peptide was dose-dependent (Fig. 3b). Interestingly, at low doses in the human MLR $(<20 \mu \mathrm{g} / \mathrm{ml})$, HLA-DQA1 peptide stimulated IL- 2 and IFN- $\gamma$ production.

Additive inbibition of buman MLR with CTLA4Ig and HLA$D Q A 1$ peptide. In addition to the initial interaction of the TCR with the MHC-peptide complex (signal 1), full T-cell activation requires a second (costimulatory) signal, the best characterized of which is that between the CD28 molecule expressed on T cells and its ligand B-7 expressed on APCs (14). CTLA4Ig is a fusion protein that blocks CD28-B7 interaction and hence costimulation. CTLA4Ig 
has previously been demonstrated to inhibit the MLR in vitro (15) and in vivo (16). As our hypothesis was that HLADQA1 peptide inhibits signal one by interfering with the interaction of the TCR with the MHC-peptide complex, we investigated the impact of combined blockade of these two pathways using suboptimal doses of HLA-DQA1 peptide and CTLAIg. We found that $0.1 \mu \mathrm{g} / \mathrm{ml}$ of CTLA4Ig resulted in $30.1 \pm 8.4 \%$ (mean \pm SEM) inhibition, and HLA-DQA1 peptide at $5 \mu \mathrm{g} / \mathrm{ml}$ resulted in 28.6 $\pm 16.5 \%$ inhibition of the human MLR, whereas the combination produced $72.4 \pm 18.1 \%$ inhibition. No such effect was seen with HLA-DQB1 peptide. Thus, the combination of low-dose CTLA4Ig and HLA-DQA1 peptide had an additive inhibitory effect. A similar effect on cytokine production was seen with both IL-2 and IFN- $\gamma$, as determined by enzyme-linked immunosorbent assay (ELISA), being reduced when the combination of lowdose CTLA4Ig and HLA-DQA1 peptide was added to cultures (data not shown). These data further support our initial hypothesis that HLA-DQ $\alpha$ may modulate the Tcell response by disruption of the TCR-MHC-peptide interaction through binding to MHC class II.

Inbibition of the indirect pathway of allorecognition with HLADQA1 peptide. We examined the ability of HLA-DQA1 peptide to inhibit the indirect pathway of allorecognition. In the indirect allorecognition pathway, peptides derived from the breakdown of donor MHC molecules are presented by self-MHC on recipient APCs, in a manner analogous to the processing of bacterial or viral antigens $(14)$. We have demonstrated previously $(7,8)$ that LEW T cells primed to the indirect pathway by immunization, or by cardiac or renal allograft, recognize and proliferate to RT1. $\mathrm{D}^{\mathrm{u}} \beta_{2}$, a peptide derived from the hypervariable region of the WF MHC class II $\beta$ chain. Cell primed in vivo by immunization with RT1.D ${ }^{\mathrm{u}} \beta_{2}$ were restimulated in vitro with this peptide in the presence of increasing doses of HLA-DQA1 peptide or HLA-DQB1 peptide. We found that there was $81.2 \pm 6.6 \%$ inhibition at $100 \mu \mathrm{g} / \mathrm{ml}(n=6)$. No inhibitory effect was seen with HLA-DQB1 peptide. Thus HLA-DQA1 peptide inhibits the indirect presentation of allopeptides. However, it is interesting to note that higher doses are required to achieve $100 \%$ inhibition of primed T cells upon restimulation, compared with the rat MLR.

Inhibition of proliferation by allospecific T-cell clones. We have established T-cell clones generated after immunization of LEW animals with the immunogenic peptide RT1.D ${ }^{\mathrm{u}} \beta_{2}$ (20-44). These RT1.D ${ }^{\mathrm{u}} \beta_{2}$-specific clones have been shown to be $\mathrm{CD}^{+}$, and reverse transcriptase (RT)-PCR transcript analysis with specific rat TCR V $\beta$ primers showed that these clones expressed V $\beta$ 9 TCR transcripts. Clone 4F2 was used for further studies and has been shown to express messages for both IL- 2 and IFN- $\gamma$ by RT-PCR and to produce IFN- $\gamma$ (by ELISA) in response to restimulation with RT1.D ${ }^{\mathrm{u}} \beta_{2}$ in vitro. Furthermore, systemic injection of the 2F4 clone to naive LEW rats can elicit an antigen-specific delayed-type hypersensitivity response against RT1.D ${ }^{\mathrm{u}} \beta_{2}$ peptide and WF splenocytes, in vivo $(10,11)$. Therefore, we tested the ability of the HLA-DQA1 peptide to suppress T-cell clone proliferative responses to RT1.D $\beta_{2}$. HLA-DQA1 peptide inhibited the proliferative response of the RT1.D $\beta_{2}$-specific Tcell clones 4F2 in a dose-response fashion, with $87 \pm 16$ (cpm) at $50 \mu \mathrm{g} / \mathrm{ml}$ HLA-DQA1 peptide compared with positive control at 18,369 $\pm 937(\mathrm{cpm})$ and background of $43 \pm$ $6(\mathrm{cpm})$. Thus, HLA-DQA1 peptide is capable of inhibiting $\mathrm{CD}^{+}$, antigen-specific Th1 clones. These data provide further evidence that this peptide exerts its effect through inhibition of CD4 function. with resultant broad-reaching immunological effects through the disruption of help, by way of cytokines, necessary for recruitment and expansion of other cell populations such as $\mathrm{CD}^{+} \mathrm{T}$ cells, B cells, and monocytes/macrophages.

Inbibition of proliferation to autoantigen. To determine whether the immunosuppressive effects of HLA-DQA1 peptide were specific to alloantigen, we used the animal model experimental autoimmune encephalomyelitis (EAE), an inflammatory disease of the central nervous system that can be induced in a number of species by immunization with MBP and adjuvant $(12,13)$. We examined the ability of HLA-DQA1 peptide to inhibit the proliferative response of lymphocytes primed to the encephalogenic peptide MBP 71-90. We found that HLA-DQA1 peptide was a potent inhibitor of proliferation to the antigenic peptide, with $97.5 \pm 5.5 \%$ inhibition at doses as low as 6.25 $\mu \mathrm{g} / \mathrm{ml}$. No inhibitory effect was seen with the control peptide. These data provide important information, as they demonstrate that the effects of HLA-DQA1 peptide are not confined to the alloimmune response; rather, it disrupts the T-cell response to, or recognition of, antigen in general. The potential therefore exists to alter the immune response not only to alloantigens but also autoantigens in the setting of autoimmune diseases. In addition, the dose required is substantially lower than that required to inhibit the response of T cells primed to RT1.D $\beta_{2}$, suggesting that the avidity of either the MHC-peptide interaction or the TCR-MHC-peptide may influence the ability of HLADQA1 peptide to inhibit the immune response.

Induction of apoptosis with HLA-DQA1 peptide. Several potential explanations existed for the mechanism mediating the inhibitory effect of HLA-DQA1, including

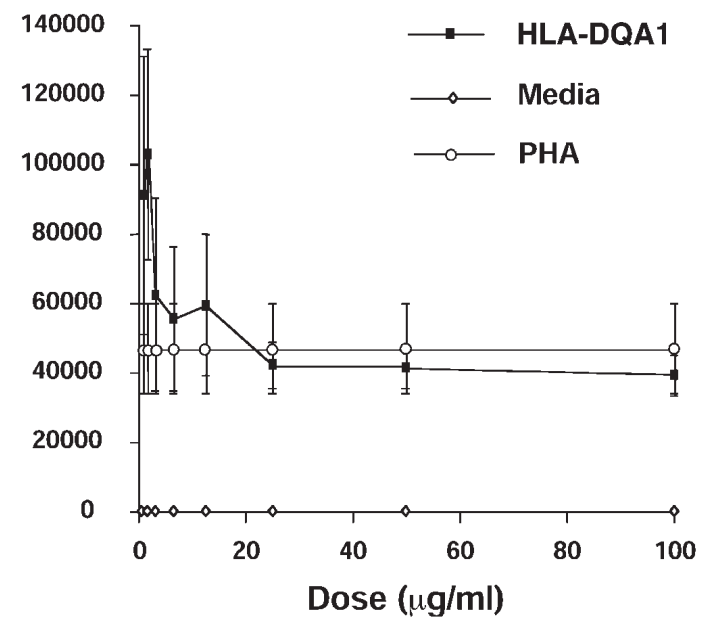

\section{Figure 2}

Effects of HLA-DQA1 peptide on PHA-induced T-cell proliferation. Human PBMCs from normal volunteers were stimulated with PHA alone or in the presence of HLA-DQA1 peptide $(100 \mu \mathrm{g} / \mathrm{ml})$. Results are expressed as cpm for each of the experimental groups and represent the mean \pm SE for four experiments. PBMCs, peripheral blood mononuclear cells. 
a

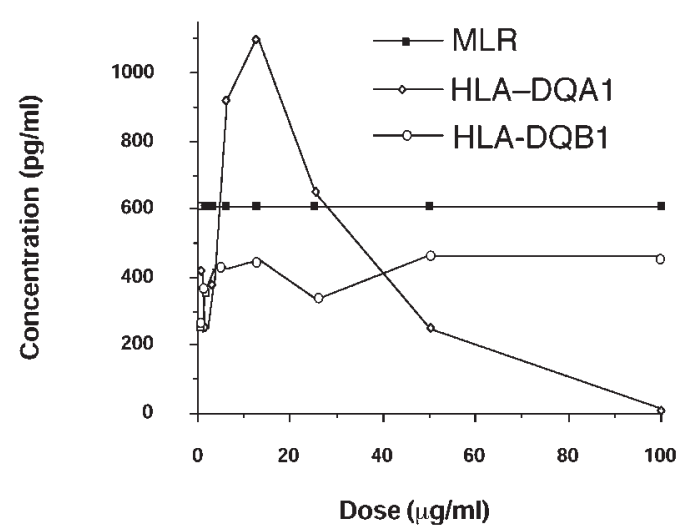

$b$

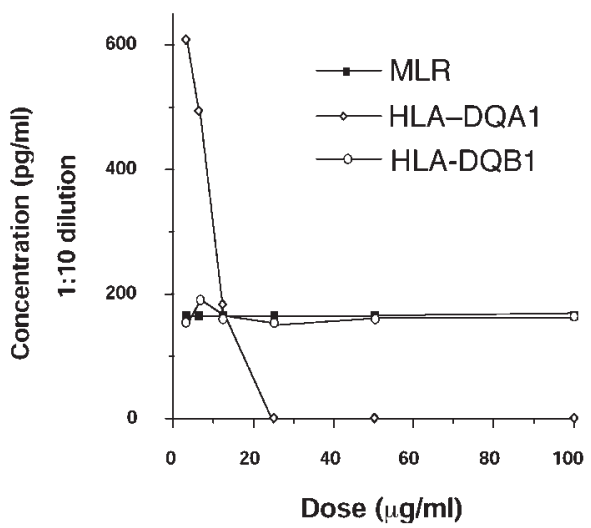

Figure 3

Effect of HLA-DQA1 and HLA-DQB1 peptides on IL-2 and IFN- $\gamma$ production in the human MLR. Supernatants from human MLRs were taken daily for 7 days following incubation either alone or in the presence of HLA-DQA1 peptide $(100-0.78 \mu \mathrm{g} / \mathrm{ml})$ or HLA-DQB1 peptide $(100-0.78 \mu \mathrm{g} / \mathrm{ml})$. Shown are IL-2 $(\boldsymbol{a})$ and IFN- $\gamma(\boldsymbol{b})$, assayed by ELISA on day 3. A biphasic effect of the HLA-DQA1 peptide on cytokine production was seen, similar to its effects on proliferation in the MLR: small doses were stimulatory, whereas larger doses were inhibitory. Results shown are representative of two separate experiments. IFN, interferon; IL, interleukin.

anergy (1), failure of recognition or ignorance as a result of MHC blockade (17), cell-cycle arrest (6), and deletion (18). Initial observations in which ethidium bromide and acridine orange uptake by cells stimulated in the presence of the inhibitory peptide HLA-DQA1 was examined suggested the occurrence of apoptosis in these cells (data not shown). To determine whether the inhibitory effect of HLA-DQA1 peptide was mediated through apoptosis, and quantitate this in an objective manner, we used flow cytometry to examine the cell cycle of RT1.D ${ }^{\mathrm{u}} \beta_{2}$-primed lymphocytes restimulated in the presence or absence of HLA-DQA1 peptide or HLA-DQB1 peptide and subsequently stained with propidium iodide. We found that after one hour of incubation, there was $5.2 \%$ apoptosis in those cells stimulated in the presence of RT1.D ${ }^{\mathrm{u}} \beta_{2}$ alone, $16.3 \%$ when HLA-DQA1 peptide was added to the culture, and 9.9\% with HLA-DQB1 peptide (Fig. 4). This increased to $14.5 \%, 69.8 \%$, and $20.77 \%$ in each respective group at 24 hours (Fig. 5). No increase in apoptosis was seen in naive LEW lymphocytes incubated with HLADQA1 peptide for 24 hours. Thus, HLA-DQA1 peptide induces apoptosis in activated $\mathrm{T}$ cells.

\section{Discussion}

The T-cell response to alloantigen involves the interaction of the TCR with the MHC molecule plus its bound peptide, either through recognition of intact MHC on the surface of donor APCs (direct pathway of allorecognition) or recognition of processed alloantigen presented in a self-restricted manner by recipient APCs (indirect pathway of allorecognition) $(14,19)$. Acknowledgment of the integral role of the MHC-bound peptide in T-cell activation by alloantigen has highlighted the potential for altering the alloimmune response by modification of the peptide ligand (5). Experimental evidence for such potential already exists. Eckels et al. (20) have demonstrated that an HLA-DR1-restricted immunodominant peptide derived from influenza virus hemagglutinin may influence the response of HLA-DR1-specific T-cell clones, resulting in inhibition of allorecognition for some clones and enhanced proliferation for others. The ability of peptides derived from MHC molecules to affect the alloimmune response was demonstrated by Harris et al. (17), who showed that the proliferation of a T-cell line with specific reactivity to a polymorphic peptide derived

Table 2

Interspecies homologies of the 62-77 $\alpha$-hellical region of the class II MI IC: $\alpha$ chain

\begin{tabular}{|c|c|c|c|c|c|c|c|c|c|c|c|c|c|c|c|}
\hline $\mathrm{DQ} \wedge 1 * 0101$ & $\wedge$ & L & $\mathrm{R}$ & $\mathrm{N}$ & M & $\wedge$ & $\mathrm{v}$ & $\wedge$ & $\mathrm{K}$ & 11 & $N$ & L & $N$ & 1 & $M$ \\
\hline DQA $1 * 0201$ & - & - & $\mathrm{T}$ & - & 1 & - & - & $\mathrm{L}$ & - & - & - & - & - & - & $\mathrm{L}$ \\
\hline DQA $1 * 03011$ & - & - & $\mathrm{T}$ & - & 1 & - & - & 1 & - & - & - & - & - & - & $\mathrm{v}$ \\
\hline$[1 Q A 1 * 0101$ & - & - & 1 & - & 1 & - & - & I & - & - & - & - & - & - & $\mathrm{L}$ \\
\hline DQA1*05011 & - & - & 1 & - & 1 & - & - & $\mathrm{L}$ & - & - & - & - & - & $\mathrm{s}$ & $\mathrm{L}$ \\
\hline טQ/1×0601 & - & - & $\mathrm{T}$ & - & 1 & - & - & $\mathrm{T}$ & - & - & - & - & - & - & $\mathrm{L}$ \\
\hline RT1. $B^{u} \alpha$ & $G_{1}$ & & Q & & 1 & & 1 & I & & & & & $\mathrm{E}$ & & L \\
\hline $\mid 1-2 A^{d} \alpha \alpha$ & 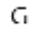 & - & $Q$ & - & 1 & - & A & [ & - & - & - & - & $c_{1}$ & - & $\mathrm{L}$ \\
\hline $\mathrm{H}-2 \mathrm{~A}^{k} \alpha$ & $c_{1}$ & - & 0 & - & 1 & - & $T$ & (i & - & - & - & - & $\Gamma$ & - & 1 \\
\hline เग12A*0101 & - & - & A & - & 1 & - & - & () & - & A & - & - & t & - & - \\
\hline$H-2 E^{\prime \prime} \alpha$ & - & - & A & - & 1 & - & - & $v$ & - & A & - & - & L & $\mathrm{V}$ & - \\
\hline RT1.D" $\alpha$ & - & - & $\wedge$ & - & 1 & - & V & v & - & $\wedge$ & - & - & $v$ & - & - \\
\hline $\mathrm{B} 1{ }^{*} 0501$ & $\mathrm{~N}$ & s & Q & K & $\mathrm{E}$ & V & $\mathrm{L}$ & $\mathrm{E}$ & $\sigma_{1}$ & $\wedge$ & $\mathrm{R}$ & $\wedge$ & 5 & V & D \\
\hline
\end{tabular}

White boxes show amino acid residues 62 // of I ILA-DQA1*0101 and corresponding sequences in other I ILA-DQA1 alleles and in DQ-like rat and mouse alleles. Correspond-

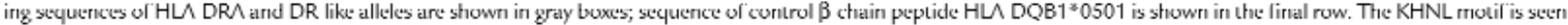

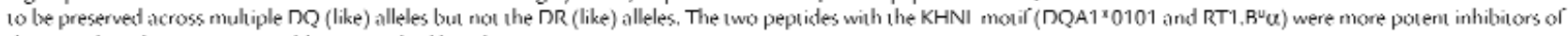
the MLR than the RI 1.1J" $\alpha$ peptide. MLR, mixed lymphocyte response. 
from the $\beta$ chain of HLA-DR1 could be efficiently blocked by adding to the culture a nonpolymorphic sequence obtained from the same domain.

Synthetic peptides representing nonpolymorphic regions of class I MHC sequence have already been studied for their immunoregulatory properties in vitro and in vivo $(5,21,22)$. Recent work has focused on relatively nonpolymorphic peptides derived from the $\alpha$ helical regions, in particular HLA-B7.75-84 and HLA-B27.75-84. In vitro, these peptides block CTL maturation or mature CTL function, or both, and in vivo, they significantly prolong allograft survival in many different rodent models. A phase II trial of HLA-B27.75-84 use in human renal allograft recipients has already been reported (23). The mechanisms of action of these class I peptides at the cellular and molecular level, although still under investigation, appear to be distinct from the nonpolymorphic peptides studied here. Proposed mechanisms include binding to immunophilin-type heat-shock proteins, interaction with the natural killer inhibitory receptor or modulation of heme oxygenase- 1 activity (24-26).

Here we provide evidence that synthetic peptides derived from a highly conserved region of the $\alpha$ chain (residues 62-77) of three class II MHC molecules are effective inhibitors of alloimmune responses in vitro. All three peptides inhibited the rat MLR independent of the responder or stimulator MHC type, whereas the fourth peptide derived from the corresponding region of the $\beta$ chain of HLA-DQB1*0501 had no such effect. Each inhibitory peptide varied in relative potency, with RT1.D $\alpha$ peptide, the least potent of the peptides, requiring 25 and 200 times higher concentration to effect the same degree of inhibition as HLA-DQA1 peptide and $\mathrm{RT} 1 . \mathrm{B} \alpha$ peptide, respectively. Interestingly, comparison of the peptide sequences revealed a possible four-amino acid motif (KHNL) that was present in the two most effective $\alpha$-chain peptides (HLA-DQA1 and RT1.B $\alpha$ ) and absent in the noninhibitory $\beta$-chain peptide (Table 2 ). The least potent $\alpha$-chain peptide, RT1.D $\alpha$, differed from the HLA-DQA1 and RT1.B $\alpha$ peptides by one amino acid within this motif: KANL, compared with KHNL. These observations suggest that the KHNL sequence may contribute to the mechanism of action of these peptides.

Inhibition of the MLR and of cytotoxic T-cell generation (but not mature cytotoxic T cell-mediated lysis of target cells) by HLA-DQA1 peptide implies that its effect is directed at $\mathrm{CD}^{+} \mathrm{T}$ cells or at an early stage in $\mathrm{CD}^{+} \mathrm{T}$ cell activation. The lack of inhibition by HLA-DQA1 peptide of mitogen-induced proliferation at concentrations causing $100 \%$ inhibition of the MLR demonstrates that the antiproliferative effect is not due to nonspecific or toxic inhibitory effects of the peptide on T cells. Thus, because there is inhibition of T-cell stimulation due to antigen, whereas no such effect is seen when the stimulus is independent of the MHC, it would appear that HLA-DQA1 peptide inhibits $\mathrm{CD}^{+} \mathrm{T}$-cell function by blocking or interfering with the MHC-TCR interaction. This hypothesis is strengthened by the inhibition of proliferation to superantigen by HLA-DQA1 peptide.

Preincubation of responder T cells with peptide followed by washing had no inhibitory effect on the MLR. Preincubation of stimulator cells followed by washing similarly had $a$
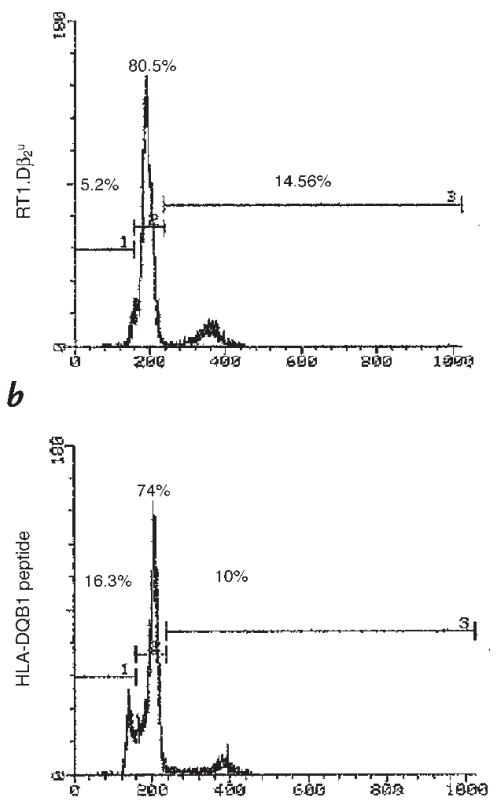

c

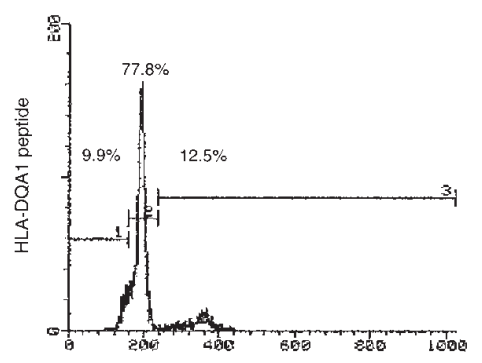

\section{Figure 4}

Induction of apoptosis by HLA-DQA1 peptide, but not by HLA-DQB1 peptide. Lymphocytes primed in vivo to RT1. D $\beta_{2}$ were restimulated with this peptide $(\boldsymbol{a})$ alone or in the presence or absence of $(\boldsymbol{b})$ HLA-DQA1 peptide $(100 \mu \mathrm{g} / \mathrm{ml})$ or $(\boldsymbol{c})$ HLA-DQB1 peptide $(100 \mu \mathrm{g} / \mathrm{ml})$. Cells were examined at $1 \mathrm{~h}$ for evidence of apoptosis as determined by propidium iodide uptake using flow cytometry. Restimulation in the presence of HLA-DQA1 peptide resulted in significant apoptosis.

no inhibitory effect. For HLA-DQA1 peptide to influence the MLR, addition of the peptide to a mixture of both cell populations was required. Delaying addition of HLADQA1 peptide to the MLR by as little as five minutes resulted in diminished inhibitory effect, with only $28.3 \%$ inhibition occurring when addition was delayed by 60 minutes. These combined data lend further support to the hypothesis that for exertion of an inhibitory effect, the HLA-DQA1 peptide requires the interaction of the T cell with the APC and affects very early events in T-cell activation.

Nonpolymorphic MHC class II-derived peptides have been shown to modulate $\mathrm{CD}^{+} \mathrm{T}$-lymphocyte function in vitro and in vivo by interfering with CD4 receptor function, but these peptides were derived from a known CD4 interacting region on the $\beta 2$ domain of murine I-A (27). The $\alpha 1$ region from which the HLA-DQA1 peptide is derived is not thought to interact directly with the CD4 molecule, so direct interference with CD4 receptor func- 
$a$

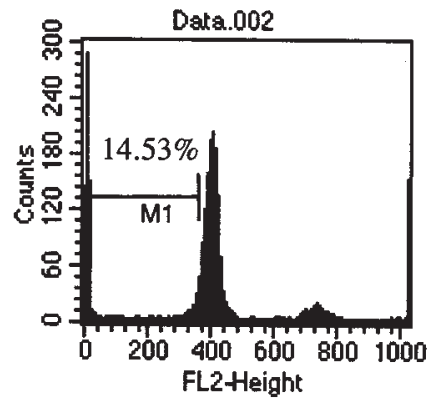

$b$

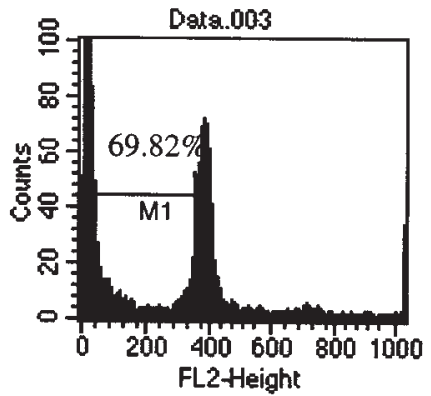

c

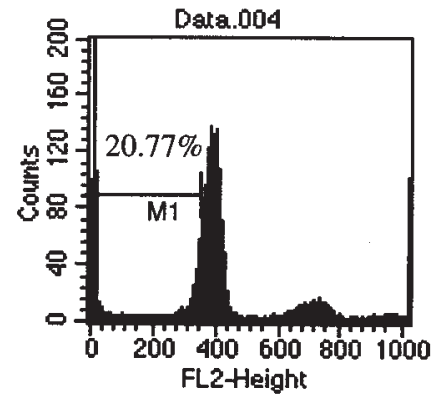

Figure 5

Quantitation of the degree of apoptosis in cells restimulated with RT1.D $\beta_{2}(\boldsymbol{a})$ alone or in the presence or absence of $(\boldsymbol{b})$ HLA-DQA1 peptide $(100 \mu \mathrm{g} / \mathrm{ml})$ or $(\boldsymbol{c})$ HLA-DQB1 peptide $(100 \mu \mathrm{g} / \mathrm{ml})$ at $24 \mathrm{~h}$. Addition of HLA-DQA1 peptide resulted in a significant increase in apoptosis relative to controls and compared with that seen after $1 \mathrm{~h}$.

tion is unlikely to explain HLA-DQA peptide's effects. In fact, this nonpolymorphic region of the $\alpha 1$ domain of class II MHC molecules forms part of the $\alpha$ helical structure of the antigen binding groove (28).

The relatively broad inhibitory effect (across different species and alleles) of the HLA-DQA1 peptide means that it is unlikely to function by TCR antagonism that is specific to the polymorphism of the TCR itself. Blockade of a conserved region on the MHC molecule (or the TCR complex) is more likely. If the HLA-DQA1 peptide functions by means of class II MHC blockade, relatively nonspecific "promiscuous" binding to different class II MHC molecules would be required. Such promiscuity of binding, at least to different alleles, has been shown to occur naturally: Elution studies have found that endogenously bound peptides derived from the peptide binding groove of $\mathrm{MHC}$ molecules can bind to different allelic forms of a class II molecule of a given locus while displaying characteristic binding motifs that relate to several, but not all, MHC alleles (3). Although such binding is nonspecific, it may still be high affinity in nature. By competing with antigen for binding to class II MHC, naturally occurring peptides may play an important regulatory role in controlling the flow of antigenic stimuli to the complementary $\mathrm{CD} 4^{+} \mathrm{T}$ cells (3). Use of sufficient amounts of the HLA-DQA1 at the time of exposure to antigen (in vitro in the MLR, and possibly in vivo, at the time of transplantation) may allow this regulatory pathway to overwhelm the antigen-presenting pathway and its ability to stimulate a normal alloimmune response.

It is also possible that the HLA-DQA1 peptide binds to class II MHC, not within the peptide binding groove, but at an alternative site critical for MHC-TCR interaction. Ligand dimerization and multimerization is a general feature of activation of cell-surface receptors, and there is structural and crystal packing evidence that the $\alpha$ and $\beta$ chains of the TCR undergo dimerization (29). There is some evidence for the in vivo formation of class II MHC dimers (30). It has been suggested that weak TCR dimers are stabilized by weak MHC dimers, resulting in a $\left(\mathrm{TCR}_{2}-\mathrm{MHC}_{2}\right)$ complex that allows more efficient signaling (29). One could postulate that the HLA-DQA1 peptide binds to class II MHC at a site critical for formation of the more stable MHC dimer, thus preventing dimerization and subsequent interaction with the TCR and possibly the CD4 coreceptor. However, the recent work of Valitutti and Lanzavecchia (31), which shows that TCR-MHC interactions are likely to involve rapid cycling of multiple TCRs per MHC molecule (rather than formation of a cross-linked "stabilized complex") implies a more active dynamic process, critical for the first half hour or so after contact - a time when the DQA1 peptide exerts its most potent inhibitory effects.

The inhibitory effect of HLA-DQA1 peptide is mediated, at least in part, through the induction of apoptosis of activated $T$ cells, with evidence of apoptosis as early as one hour after stimulation. It has been shown previously (32) that engagement of the TCR with the MHC-peptide complex can result in apoptosis. Zavazava and Kronke (18) have shown that stimulation of cytotoxic $T$ cells by soluble class I MHC molecules in the absence of costimulation is associated with the upregulation of Fas-L and induction of apoptosis. In addition, Rhode et al. (33) reported on the induction of apoptosis by a single-chain MHC class II molecules. Different ligands, such as antibodies, superantigen, and agonist and antagonist peptide-MHC complexes, may produce different responses ranging from activation to inhibition depending on which tyrosine kinases are brought into proximity, the stability of the interaction, and the resulting pattern of tyrosine phosphorylation (34). Furthermore, the ability of altered activation of ZAP70 to result in apoptosis is suggested by data from Skov et al. (35). HLA-DQA1 peptide may alter T-cell signaling by either binding within the groove or through disrupting the TCR-MHC interaction, with resultant induction of apoptosis.

Interestingly, Boytim et al. (6) report that a peptide derived from a similar region of another HLADQA1 allele (HLA-DQA ${ }^{*} 03011$, residues $65-79$ ) has immunosuppressive effects in vitro. There is significant similarity in the amino acid sequences between the DQA1*0101(62-77) and DQA1*03011(65-79) allelic peptides; within the overlapping region, they differ by 
only three amino acids, with the four amino acids KHNL being conserved. The in vitro effects of the HLADQA $1 * 03011$ peptide resemble the peptide described here in that antigen-stimulated lymphocyte proliferation is inhibited in a nonallele-specific manner, but they differ in that early events in T-cell activation are not affected, as continued inhibitory effects are seen when the addition of the peptide to culture is delayed by as much as 24 hours. In addition, mitogen-stimulated lymphocyte proliferation is also inhibited. This HLA-DQA1*03011 peptide appears to function by inhibition of cyclin-dependent kinases, thus arresting cell-cycle progression. Its binding site has yet to be determined. Further work is required to determine how distinct its mechanisms of action and binding sites are from those of the HLA-DQA $1 * 0101$ peptide. It is interesting, however, that limited differences in the peptides' amino acid sequences results in very different mechanisms of action.

In summary, these data demonstrate that synthetic peptides derived from highly conserved regions of the class II MHC $\alpha$ chain can modulate $\mathrm{CD}^{+}{ }^{+} \mathrm{T}-$-lymphocyte function by affecting an early event in $\mathrm{CD} 4^{+} \mathrm{T}$-cell activation, most likely normal signaling between the TCR and the $\mathrm{MHC}$-peptide complex. As activation of specific $\mathrm{CD}^{+}{ }^{+} \mathrm{T}$ lymphocytes plays a crucial role in the genesis of alloimmune and autoimmune responses, these in vitro studies provide the initiative to study the in vivo effects of these agents in modifying the course of allograft rejection or autoimmune disease. Combined use with CTLA4Ig may prove particularly effective in vivo, as an additive immunomodulatory effect was noted in these experiments. Further elucidation of the mechanisms mediating the induction of apoptosis and exact binding sites of these immunomodulatory peptides may also allow design of more potent and specifically acting derivatives for in vivo use in experimental animals and humans.

\section{Acknowledgments}

M.H. Sayegh is a recipient of the NKF Clinician Scientist Award. This work was supported by a research grant from the National Institutes of Health (NIH) (RO1 AI33100-06 and AI 34965). B. Murphy is supported by a grant from the NIH (AI 0 1538-02).

1. Sloan-Lancaster, J., Evavold, B., and Allen, P. 1993. Induction of T-cell anergy by altered T-cell-receptor ligand on live antigen-presenting cells. Nature. 363:156-159.

2. Chicz, R.M., et al. 1992. Predominant naturally processed peptides bound to HLA-DR1 are derived from MHC-related molecules and are heterogeneous in size. Nature. 358:764-768.

3. Chicz, R.M., et al. 1993. Specificity and promiscuity among naturally processed peptides bound to HLA-DR alleles. J. Exp. Med. 178:27-47.

4. Hunt, D.F., et al. 1992. Peptides presented to the immune system by the murine class II major histocompatibility complex molecule I-Ad. Science. 256:1817-1820.

5. Magee, C.C., and Sayegh, M.H. 1997. Peptide-mediated immunosuppression. Curr. Opin. Immunol. 9:669-675.

6. Boytim, M.L., et al. 1998. Inhibition of cell cycle progression by a synthetic peptide corresponding to residues 65-79 of an HLA class II sequence: functional similarities but mechanistic differences with the immunosuppressive drug rapamycin. J. Immunol. 160:2215-2222.

7. Gallon, L., et al. 1995. Indirect pathway of allorecognition: the occurrence of self-restricted $\mathrm{T}$ cell recognition of allo-MHC peptides early in acute allograft rejection and its inhibition by conventional immunosuppression. Transplantation. 59:612-616
8. Watschinger, B., Gallon, L., Carpenter, C.B., and Sayegh, M.H. 1994. Mechanisms of allorecognition: recognition by in vivo primed T-cells of specific major histocompatibility complex polymorphisms presented as peptides by responder antigen-presenting cells. Transplantation. $\mathbf{5 7 : 5 7 2 - 5 7 7 . ~}$

9. Sayegh, M.H., et al. 1991. Effects of BWH-4 anti-CD4 monoclonal antibody on rat vascularized cardiac allografts before and after engraftment. Transplantation. 51:296-299.

10. Waaga, A.M., et al. 1997. Mechanisms of indirect allorecognition: characterization of MHC class II allopeptide-specific T helper cell clones from animals undergoing acute allograft rejection. Transplantation. 65:876-883.

11. Chen, W.J., et al. 1996. Mechanisms of indirect allorecognition: class II MHC allopeptide-specific T cell clones transfer delayed type hypersensitivity responses in vivo. Transplantation. 62:705-710.

12. Khoury, S.J., et al. 1993. Acquired tolerance to experimental autoimmune encephalomyelitis by intrathymic injection of myelin basic protein or its major encephalitogenic peptide. J. Exp. Med. 178:559-566.

13. Khoury, S.J., et al. 1995. Mechanisms of acquired thymic tolerance in experimental autoimmune encephalomyelitis: thymic dendriticenriched cells induce specific peripheral $\mathrm{T}$ cell unresponsiveness in vivo. J. Exp. Med. 181:357-366.

14. Sayegh, M.H., and Turka, L.A. 1998. The role of T-cell costimulation in transplant rejection. N. Engl. J. Med. 338:1813-1821.

15. Turka, L.A., et al. 1992. T-cell activation by the CD28 ligand B7 is required for cardiac allograft rejection in vivo. Proc. Natl. Acad. Sci. USA. 89:11102-11105.

16. Akalin, E. 1996. CD28-B7 T cell costimulatory blockade by CTLA4Ig in the rat renal allograft model: inhibition of cell-mediated and humoral immune responses in vivo. Transplantation. 62:1942-1945.

17. Harris, P.E., Zhuoru, L., and Suciu-Foca, N. 1992. MHC class II binding of peptides derived from HLA-DR1. J. Immunol. 148:2169-2174.

18. Zavazava, N., and Kronke, M. 1996. Soluble HLA class I molecules induce apoptosis in alloreactive cytotoxic T lymphocytes. Nat. Med. 2:1005-1010.

19. Sayegh, M.H., and Carpenter, M.H. 1996. Role of indirect allorecognition in allograft rejection. Int. Rev. Immunol. 13:221-229.

20. Eckels, D.D., Gorski, J., Rothbard, J., and Lamb, J.R. 1988. Peptide-mediated modulation of T-cell allorecognition. Proc. Natl. Acad. Sci. USA. 85:8191-8195.

21. Murphy, B., and Sayegh, M.H. 1996. Immunomodulatory function of MHC-derived peptides. Curr. Opin. Nephrol. Hypertens. 5:262-268.

22. Sayegh, M.H., and Krensky, A.M. 1996. Novel immunotherapeutic strategies using MHC derived peptides. Kidney Int. 49:S13-S20.

23. Giral, M., et al. 1997. Decreased cytotoxic activity of natural killer cells in kidney allograft recipients treated with human HLA-derived peptide. Transplantation. 63:1004-1011.

24. Krensky, A.M., and Clayberger, C. 1997. HLA-derived peptides as novel immunosuppressives. Nephrol. Dial. Transplant. 12:865-868.

25. Nossner, E., et al. 1996. HLA-derived peptides which inhibit T cell function bind to members of the heat-shock protein 70 family. J. Exp. Med. 183:339-348.

26. Iyer, S., et al. 1998. Characterization and biological significance of immunosuppressive peptide D2702.75-84 (E-V) binding protein. J. Biol. Chem. 273:2692-2697.

27. Shen, X., et al. 1996. Peptides corresponding to CD4-interacting regions of murine MHC class II molecules modulate immune responses of CD4+ $\mathrm{T}$ lymphocytes in vitro and in vivo. J. Immunol. 157:87-100.

28. Paliakasis, K., et al. 1996. Novel structural features of the human histocompatibility molecules HLA-DQ as revealed by modeling based on the published structure of the related molecule HLA-DR. J. Struct. Biol. 117:145-163.

29. Fields, B.A., et al. 1995. Crystal structure of the V alpha domain of a T cell antigen receptor. Science. 270:1821-1824.

30. Brown, J.H., et al. 1993. Three-dimensional structure of the human class II histocompatibility antigen HLA-DR1. Nature. 364:33-39.

31. Valitutti, S., and Lanzavecchia, A. 1997. Serial triggering of TCRs: a basis for the sensitivity and specificity of antigen recognition. Immunol. Today. 18:299-304.

32. Mueller, D.L., and Jenkins, M.K. 1995. Molecular mechanisms underlying functional T-cell unresponsiveness. Curr. Opin. Immunol. 7:375-381.

33. Rhode, P.R., et al. 1996. Single-chain MHC class II molecules induce T cell activation and apoptosis. J. Immunol. 157:4885-4891.

34. Fields, B.A., and Mariuzza, R.A. 1996. Structure and function of the Tcell receptor: insights from X-ray crystallography. Immunol. Today. 17:330-336.

35. Skov, S., Bregenholt, S., and Claesson, M.H. 1997. MHC class I ligation of human T cells activates the ZAP70 and p56lck tyrosine kinase, leads to an alternative phenotype of the TCR/CD3 zeta chain, and induces apoptosis. J. Immunol. 158:3189-3196. 